\title{
Research and Development Spending and Technical Efficiency: Evidence from Biotechnology and Pharmaceutical Sector
}

\author{
Kevin Grant, Roman Matousek, Martin Meyer \& Nickolaos G. Tzeremes
}

\begin{abstract}
Set within the expenditure context of the global financial crisis (GFC), this paper explores how the research and development $(R \& D)$ expenditures of biotechnology and pharmaceutical companies affect their technical efficiency levels. A balanced panel of 149 U.S. firms operating in biotechnology and pharmaceutical sector (covering the period 2000-2017) was employed. Output-oriented partial frontier measures were used to measure the effect of R\&D expenditure on firms' technical efficiency levels. Findings suggest that company efficiency is an important contributor on the effects of R\&D on productivity and efficiency. Result suggests that a relationship between technical efficiency and R\&D expenditure exhibits a "U"-shape relationship. The estimated efficiency of biotechnology firms is higher compared to pharmaceutical firms driven by their higher R\&D expenditure levels. We demonstrate that $R \& D$ expenditures are essential for firm efficiency. We posit that a threshold level for achieving optimal efficiency levels exist, which can be used to inform managerial and policy-making decisions at the firm level.
\end{abstract}

Keywords: R\&D efficiency; technology; innovation; data envelopment analysis; U.S. biotechnology and pharmaceutical firms. 


\section{Introduction}

The global financial crisis (GFC) has imposed unprecedented financial constraints on corporate spending across different business sectors (Campello et al., 2010). Coupled with the Dodd-Frank Act in the United States, the issue of return on innovation has never been so important. Yet, the following question remains: what is the most optimal point to investment in new technology, new products and services, etc.?

Biotechnology and pharmaceutical (B\&P) firms have historically been less exposed to the economic fluctuations of global economics due to their scale, share-gearing and historic success in the innovation cycle from research and development (R\&D) investments (Mazzucato \& Parris, 2014). We contend that the 'credit crunch' from the outset of the GFC reduced available funding for B\&P firms, which affected their ability to continue to develop, cultivate and maintain the same level of return from their innovation pipelines. This contention is informed by statistical analysis of a balanced panel (covering the period 2000-2017) of 149 U.S. biotechnology and pharmaceutical firms. The period for this analysis captures the effect of R\&D on the performance of companies before, during and after the GFC (Lee et al., 2015). We specifically targeted companies with a Standard \& Poor's Global Industry Classification Standard (GICS) equal to '35202010’ that operate United States.

In addition to the lack of financial resources in R\&D affected by the GFC the global pharmaceutical and biotechnology industry has been evolving in the last few decades (McKinsey 2017). Patent expiries, weak new dug regime pipelines, regulatory changes, product withdrawals poorer R\&D productivity, new payers and internet savvy beneficiaries (such as cancer and aids charities and campaign groups) have been pushing back on the cost of treatments, have and are challenging the development and sustainability of this market. The need to ensure greater productivity may have forced $\mathrm{B} \& \mathrm{P}$ firms to hone their $\mathrm{R} \& \mathrm{D}$ activities. What remains unclear - is there a tipping point for such investments and do the increases and decreases in $R \& D$ investment follow the same pattern of return?

We acknowledge that innovation and its management has a much broader scope than just $R \& D$ expenditures or patents. Brand innovation is often perceived as being more 
important than technical innovation in terms of its direct impact on growth and margins. It is difficult to measure such intangible results; therefore, we use $R \& D$ expenditures as a proxy for innovation activity and value.

This paper advances the existing discussion on the role and place of $R \& D$ expenditures has within the GFC context of spending and returns at the corporate level. This research is needed at this time because the financial squeeze has prompted $\mathrm{B} \& \mathrm{P}$ firms to consolidate their activities. It is estimated that approximately $88,000^{1}$ pharmaceutical employees, including scientists in $R \& D$ units were displaced between 2009 and 2013 (Wang, 2014). This displacement equates to a $187 \%$ reduction in the workforce that engages in the ideation and invention stages of the innovation process.

The B\&P industry is connected to high levels of $\mathrm{R} \& \mathrm{D}$ activity, but given the credit squeeze is this still the case? Understanding the nature of R\&D efficiency and its elements is essential for designing $R \& D$ policies that effectively nurture innovation and promote technological progress. We contend there may be a tipping point, were too much R\&D activity hampers innovation.

The $\mathrm{B} \& \mathrm{P}$ industry has also engaged in restructuring via mergers and acquisitions [M\&As] (Wang, 2014). These changes were exclusively driven by the financial objective of firms to maintain or enhance profitability or scale up. Booz and Company (2009), demonstrated that the Dow Jones U.S. Pharmaceutical Index fell by only 15\%, compared to the Dow Jones Industrial Average of 38\% between June 2008 and March 2009. To combat this decline, the pharmaceutical industry has reduced costs over the last decade. Pharmaceutical companies have either cut costs on a standalone basis or more aggressively through mergers or culture management of expense capital items (Wang, 2014).

B\&P firms allocate five times more investment to $R \& D$ relative to their sales than the average U.S. manufacturing firm because they want to or need to invest in their longterm success via the innovation pipeline for new products and services. It has been observed that the productivity and efficiency of R\&D in the B\&P industry has

\footnotetext{
${ }^{1}$ Source: Compiled by MHBK/IRD based on public company reports in Wang (2014).
} 
declined (Scannell et al., 2012; Pammolli et al., 2011) or flat lined (Wang, 2014). Pfizer dramatically cut R\&D spending from \$11bn before their merger in 2009, (\$7.6bn from Pfizer and \$3.4bn from Wyeth) to \$6.55bn in 2013, which is even lower than Pfizer's standalone R\&D spending. ${ }^{2}$

The productivity of $\mathrm{R} \& \mathrm{D}$ is measured by the number of new drugs that are approved and introduced to markets relative to R\&D expenditures (Scannell et al. 2012). Many $\mathrm{B} \& \mathrm{P}$ companies have narrowed their business focuses and pooled their assets to create category leaders in an attempt to deliver short-term innovation gains. Scannell et al. (2012) estimate that the number of newly introduced drugs per billion U.S. dollars spent on R\&D has halved every nine years since 1950. As Pammolli et al. (2011) clarify, this decline is the result of diminishing returns in the knowledgeproduction function and a change in strategic direction, either to an innovation leadership strategy whereby the organisation focuses on scientific innovation or a focused niche strategy whereby non-traditional diseases are targeted. As such, R\&D expenditures and intensities can be used as proxies for innovation.

Changes in the management of commercial $R \& D$, along with intensive pressure from shareholders to maximise short-term profits, have also decreased the probability of success across the industry from pursuing longer term research and development projects. Thus, commercial research by companies has focused on commercial success rather than grand societal challenges and sustainable innovation products (Zanders, 2011).

Based on the above structural changes across the B\&P sector, this paper advances the thinking on the role of $R \& D$ has in the biotechnology \& pharmaceutical industry. It also builds upon the current conversations Delgado-Verde et al, 2016; Brem et al, 2016) and in the Pharma sector Lowman (2012), while offering an alternative narrative and methodology.

This paper differs from previous research on R\&D in the B\&P industry (e.g., Pammolli et al., 2011; Kessel, 2011; Scannell et al., 2012) as it assesses how the R\&D

\footnotetext{
${ }^{2}$ Compiled by MHBK/IRD based on data from Capital IQ sourced in Wang (2014).
} 
expenditures of the companies affect their technical efficiency levels. The paper builds on the early work by Hossein Safizadeh and Murphy (1992) which provides the mechanism under which the R\&D expenditure increases firms' value creation through the generation of new product development. We further contribute to the study by Co and Chew (1997) in which they provide evidence that the R\&D investment preferences are directly linked with manufacturing firms' technical efficiency levels.

This paper acknowledges that many firms have switched to more open innovation and co-creation eco-systems as illustrated by Lilly's FIPNet strategy. This paper does not explore this trend, but rather explores the relationship between the productivity of the companies in terms of $\mathrm{R} \& \mathrm{D}$ expenditure and new products. We determine how these firms can improve production factors to maximise their value added. Numerous studies in different sectors and industries have used this type of analysis (e.g., Tsaur et al. 2017; Wang et al., 2015; Castellani \& Pieri, 2013; O’Mahony \& Vecchi, 2009; Chang \& Chen, 2008) limited research on B\&P firms exists (e.g., Hashimoto \& Haneda, 2008; González \& Gascón, 2004).

Only a few studies explore the problem of productivity and efficiency in the B\&P industry using company level data, and no studies have modelled in an efficiency framework, the direct effect between investment and value added. Hashimoto and Haneda (2008) analyse the efficiency of Japanese pharmaceutical companies, while González and Gascón (2004) analyse sources of growth in productivity in the Spanish pharmaceutical industry. Other studies (Pammolli et al., 2011; Kessel, 2011; Scannell et al., 2012) have used aggregated data in their analyses, but they do not provide the level of detail required, nor do they suggest any policy changes to managerial activity to maximise returns on innovation from technical efficiencies.

Most studies establish statistical associations and provide no causal direction, any managerial policy discussion can only be indicative rather than directive, which is limiting.

We posit an alternative methodological framework to estimate the efficiency of companies. We advance the current empirical research on efficiency and the productivity of $\mathrm{R} \& \mathrm{D}$ by applying a nonparametric framework that is based on 
methodological developments regarding conditional efficiency measures. This enables the dynamic effects of $R \& D$ expenditures on the levels of production efficiency in a sample of 149 B\&P companies between 2000 and 2017 to be captured. These sample companies were selected based on market performance via sales coupled with strong stakeholder and shareholder value for the period under investigation, using mean analysis.

This approach is advantageous since contradictions exist in the limited amount of literature that exists, which is beset by differing methodological and practical considerations. The advantages of this approach are; first, the results in earlier studies may be contradictory because the a priori assumption concerning the functional form of the examined relationship could be erroneous when deploying parametric techniques. Second, the different methodological (econometric adopted) frameworks may be another potential source of conflicting results given the ideological premise. Third, the different datasets applied in the studies may cause ambiguity, particularly when involving differing periods and types of firms from different origins that operates in different markets. Fourth, the variables omitted from the empirical model, could affect the overall results and produce further inconclusive findings.

To enrich the debate on how to measure and evaluate a firm's performance and to offset earlier methodological issues, a new time-dependent conditional frontier model (Mastromarco \& Simar, 2015) was utilised, following recent advances advocated by Bădin et al. (2012, 2014). In contrast to the traditional DEA approaches (Window Analysis or Malmquist Productivity Index), dealing with multiple time periods may be troublesome (Cooper et al., 2007). Probabilistic DEA framework allows researchers and evaluators to capture the effect of $R \& D$ expenditure in a dynamic framework (time-dependent) that incorporates different periods and phenomena (e.g., the GFC) into performance measurement.

Furthermore, any nonlinearity that may be present in the examined relationship without prior assumptions about the functional forms in terms of the estimated production function of the companies or the effects of $R \& D$ expenditures on their estimated technical efficiency levels are addressed. 
This paper provides the following intellectual contributions: 1) it unpacks the notion that it may be beneficial not to impose or adopt a separability assumption (Daraio et al., 2018), and 2) it assumes that the variables which influence firms' production process (i.e., time and R\&D expenditures) directly affect the shape of the estimated production frontier (i.e., the separability condition does not hold true). As a result, the obtained efficiency estimates are determined by the firms' production inputs and outputs alongside with time and R\&D expenditures (Simar and Wilson 2011).

This paper is structured as follows: Section 2 provides a synthesis of the contemporary research on the productivity and efficiency of R\&D. A summary of the most contemporary methodological approaches for assessing a firm's efficiency is presented. Section 3 details the methodological framework used in this research, followed by a presentation of the findings and a discussion. Section 4 provides conclusions and proposes policy recommendations based on our analysis.

\section{Review of the related literature}

The concept of productivity is the expected indicator of efficiency in any productionbased system, yet various levels of analysis are used-individual, company, sector, and discipline, region, national and international data sets are often subjected to different interpretations. It is difficult to measure the total effects of the production factors. Whilst several parametric and non-parametric approaches have been used to handle the complexity associated with measuring productivity, each has limitations and benefits. Regardless of the method adopted, the correct identification of input and output indicators is critical for the reliability of results. Approaches that capture and measure productivity are constrained by and generally steeped in ideas that were created during the manufacturing era.

This centrality of measuring efficiency is grounded in the mathematical and industrial era ('what can easily be counted'). However, we propose to offer a more neo-liberal approach, that focuses on evaluating 'what really counts'.

The following review is divided into two themes. First, we look at studies that deal with the excessive effects of $R \& D$ on productivity and growth in general terms. Then, we focus directly on $\mathrm{R} \& \mathrm{D}$ productivity in the $\mathrm{B} \& \mathrm{P}$ industry. 
Empirical studies have explored the links between $R \& D$, total factor productivity (TFP) and economic growth across different industries (sectors), however, they tend to use aggregated data at the country or industry level to demonstrate this relationship. Individual company data is still not frequently or extensively used in such studies. One reason could be the restricted access to this type of data (Venturini, 2015), but also, that methodological protocols do not favour such data from being used. Early studies, such as Griliches and Lichtenberg (1984), Coven and Levinthal (1989) and Grossman and Helpman (1991) among others, recognise the importance of R\&D as a key component of TFP. These links are well documented and often taken for granted in empirical studies (Mairesse \& Sassenou, 1991; Hall \& Mairesse, 1995) remain unchallenged, yet these studies, confirm the direct link between R\&D and company productivity in the 1980s. Building on the earlier work of Mairesse and Sasseneou (1991) who conducted a survey of econometric studies advocate that most of studies in the domain confirm a positive relationship between $R \& D$ and productivity. The work of Hall and Mairesse (1995) questions this comparability across studies in terms of defining the applied variables and estimation techniques correctly, especially given the different epistemological, methodological and practical research designs used in the studies. In addition, much of the work of 'proving' a direct link tends to see R\&D and TEP as heterogeneous activities, even though they are often treated as homogeneous activities in the literature.

It is often assumed that a positive and significant link exists between $R \& D$ and company productivity. It is interesting that this research thread tends to categorise each company into two categories: innovative and non-innovative firms. The oftenreported results confirm the hypothesis that the return on $R \& D$ is higher for more innovative companies, Griffith et al. $(2004,2006)$ extend this research on the traditional role of R\&D as a stimulator for company innovation.

We argue that by omitting the absorptive capacity of $\mathrm{R} \& \mathrm{D}$ provides biased results, suggesting that a new methodological approach should be posited, such as a networkbased DEA. The work of O'Mahony and Vecchi (2009) furthers this argument by highlighting the need to use both company accounts and industry data to make sense of the link between R\&D spending, innovation and TFP. Their study combines R\&D 
and human capital to explore productivity in R\&D in skill-intensive industries. Venturini (2015) enriches the conversation regarding the role of technology spillovers in productivity growth has. At the firm level, $R \& D$ is an intentional activity and if this has positive effects on productivity via greater levels of efficiency as new product or new production mode deliver return. This is partly misguided, as they are likely to be upstream and downstream benefits from the innovation that may not be attributed to the innovation itself.

In terms of a methodological protocol, most studies that focus on R\&D and productivity are based on the estimation parametric function. While the CobbDouglas production function is deployed in such studies, few studies in the biotechnology \& pharmaceutical industry have used this function to directly investigate the productivity relationship with $R \& D$ investments.

Pammolli et al. (2011) clarify the complexity of measuring the productivity of R\&D in this industry. Pammolli et al. (2011) argue that the simple ratio of R\&D expenditures to newly approved drugs does not reflect fully the changes in the $\mathrm{B} \& \mathrm{P}$ companies in terms of 'dark innovation'. Dark innovation suggests that much innovation activity is hidden and goes unrecognised and unmeasured and may be negative, and that existing measures do not capture all forms of innovation within an organisation, such as managerial behaviours and values, due to well-intended researchers, being trapped in entrenched preconceptions and bias about how innovation works. Pammolli et al. (2011) also show that the rate of introduction of new molecular entities has remained rather constant and attrition rates have risen. Pammolli et al. (2011) propose that other non-partisan measures are needed to estimate productivity by analysing trends in attrition rates and development times. Their work concludes that lower productivity can be explained by the low productivity of success.

Scannell et al. (2012) also attempted to develop 'new measures' to identify the factor(s) that have caused the decline in pharmaceutical R\&D efficiency. This study is significant because it provides an analytical framework that reveals how pharmaceutical companies approach productivity. Despite extensive research on company efficiency and productivity, there is limited ability to apply this research to 
biotechnology \& pharmaceutical companies, because a limited number of studies have considered R\&D and its effects on company productivity in this industry. Using the Malmquist Productivity Index, González and Gascón (2004) conclude that technical efficiency improvements led to changes in productivity in the pharmaceutical industry, yet improvement and its associated growth were small.

We identify four gaps in the current conversation:

1) No studies have explored the quantitative side of $R \& D$ excess on return, which represents the optimal utilization of inputs in the production process in B\&P firms. $\mathrm{B} \& \mathrm{P}$ companies are driven by profit maximisation (optimisation) for shareholder return and brand image, which determines the influx of $R \& D$ investment from investors (shareholders). Such an analysis would show and determine the optimal R\&D expenditures for maximising company efficiency. 2) An analysis of the effects of the GFC on the efficiency of B\&P firms and the use of R\&D investment would provide policy information and inform strategic decisions. 3) Current methodological frameworks are based on the Cobb-Douglas production function even though linear programming techniques might be more appropriate when attempting to make sense of the relationship between technical innovations and sales turnover. 4) González and Gascón (2004) and Hashimoto and Haneda (2008) suggest a method of analysing productivity across companies; however, they do not directly include R\&D in their model.

\section{Data and Methodology}

\subsection{Variable description}

The sample consists of a balanced panel (covering the period 2000-2017) of 149 U.S. B\&P firms (see Appendix 1 for company names), 97 of which operate in the biotechnology sector and 52 of which operate in the pharmaceutical sector. The period for this analysis captures the effect of $R \& D$ on the performance of companies before, during and after the GFC (Lee et al., 2015). The data was extracted from the Compustat database. We specifically targeted companies with a Standard \& Poor's Global Industry Classification Standard (GICS) equal to '35202010' and 
'35201010' that operate in the biotechnology and the pharmaceutical industries in the United States.

Companies with complete records during the examined period and recorded R\&D expenditures were included. As a result, the final data sample for the entire period consists of 2,682 observations. In order to measure the technical efficiency levels of the companies, we applied a production function framework that uses the number of employees (measured in thousands) and the value of property, plants and equipment (measured in thousands of U.S. dollars) as input factors. Moreover, we use the value added (measured in thousands of U.S. dollars) as companies' production output whereas, the R\&D expenditures (measured in thousands of U.S. dollars) are used as the factor that direct influence companies' estimated technical efficiency levels.

Table 1 presents diachronically the variables used in our analysis. The mean values presented in Table 1 indicate a decrease in R\&D expenditures from 2008-2009, suggesting that the beginning of the GFC had a direct negative effect on this value. Figure 1a also presents the mean R\&D expenditures (in logarithmic form) and their 95\% confidence intervals based on whether they operated in biotechnological or pharmaceutical sectors. The figures shows that companies operating in pharmaceutical had higher $R \& D$ expenditures. It was also noted that $R \& D$ expenditures decreased in both cases at the start of the GFC in 2008. Figure 1b presents the $R \& D$ intensity levels ( $R \& D$ expenditures over company sales) for companies operating in biotechnological and those operating pharmaceutical sectors. It appears that the companies operating in biotechnological sector have higher R\&D intensity than those operating in pharmaceutical sector. It is also evident that the R\&D intensity of the companies decreased when the GFC started. This finding verifies the findings of Lee et al. (2015) who demonstrated the negative effect of the financial crisis on the innovation capacities of companies.

\section{Table $1 \&$ Figure 1 about here}

\subsection{Efficiency measurement}

Daraio and Simar (2005, 2006, 2007a, 2007b) examine the data-generating process (DGP) that characterises the production process of companies when different factors 
are assumed to have a direct influence on the estimated process. Using this methodological framework, Bădin et al. $(2012,2014)$ further extend the analysis of the technical efficiency levels of companies with the presence of such factors both under full ${ }^{3}$ and robust (also called 'partial') $)^{4}$ frontiers. Mastromarco and Simar (2015) recently introduced the dynamic framework of these conditional efficiency measures. Based on those developments, we apply a time-dependent version of the conditional Order- $m$ frontiers to examine the effects of $R \& D$ expenditures on the technical efficiency levels of companies. Let the production process of the companies be characterised as

$\Psi=\{(x, y) \mid x$ can produce $y\}$,

where $X \in R_{+}^{p}$ and $Y \in R_{+}^{q}$ denote the input and output vectors, respectively.

Furthermore, let $Z \in R_{+}^{d}$ denote the vector of $\mathrm{R} \& \mathrm{D}$ expenditure that influence the production processes of the companies. Then, the conditional attainable set can be characterised as:

$\Psi^{z}=\{(x, y) \mid Z=z, x$ can produce $y\}$.

As Daraio and Simar (2005, 2006, 2007a, 2007b) suggest, the representation in (1) can be represented as:

$\Psi=\left\{(x, y) \mid H_{X, Y}(x, y)>0\right\}$,

where $H_{X, Y}(x, y)=\operatorname{Prob}(X \leq x, Y \geq y)$.

Then, by assuming the free disposability of inputs and outputs, the unconditional output oriented by Farrell (1957) and Debreu's (1951) technical efficiency measure of a company operating at a point $(x, y)$ can be defined as:

$$
\lambda(x, y)=\sup \{\lambda \mid(x, \lambda y) \in \Psi\}=\sup \left\{\lambda \mid S_{Y \mid X}(\lambda y \mid x)>0\right\}
$$

where $S_{Y \mid X}(y \mid x)=\operatorname{Prob}(Y \geq y \mid X \leq x)$, which is the conditional survival function of $Y$ given that $X \leq x$. Then, by following Mastromarco and Simar (2015), we add time $T$ as an additional conditional variable. For each period, $t$, the attainable set

\footnotetext{
${ }^{3}$ Several data envelopment analysis (DEA) papers apply full frontiers in order to investigate innovation and R\&D efficiency problems (e.g., Groot and García-Valderrama, 2006; Wang and Huang, 2007; Hashimoto and Haneda, 2008).

${ }^{4}$ According to Daraio and Simar (2007a), Order- $m$ frontiers are more robust for outliers than for full frontiers. They also have the same rate of convergence of parametric estimators; therefore, the wellknown dimensionality problem is avoided.
} 
$\Psi_{t}^{z} \subset R_{+}^{p+q}$ can be characterised from the support of the following conditional probability:

$$
H_{X, Y \mid Z}^{t}(x, y \mid z)=\operatorname{Prob}(X \leq x, Y \geq y \mid Z=z, T=t) .
$$

Then, the time-dependent conditional output oriented by Farrell (1957) and Debreu's (1951) technical efficiency measure of a company operating at $(x, y) \in \Psi_{t}^{Z}$ can be defined as:

$\lambda_{t}(x, y \mid z)=\sup \left\{\lambda \mid(x, \lambda y) \in \Psi_{t}^{Z}\right\}=\sup \left\{\lambda \mid S_{Y \mid X, Z}^{t}(\lambda y \mid x, z)>0\right\}$,

where $S_{Y \mid X, Z}^{t}(y \mid x, z)=\operatorname{Prob}(Y \geq y \mid X \leq x, Z=z, T=t)$.

For our analysis, we follow Cazals et al. (2002) to apply the Order- $m$ frontier, which is defined as the benchmark of the best practice among $m$ companies drawn at random from a population of companies using fewer inputs than $x$. Let $m$ i.i.d. random variables $Y_{i}, i=1, \ldots, m$ be generated according to the survival $S_{Y \mid X}(y \mid X \leq x)$ in order to define the random set as:

$\Psi_{m}(x)=\left\{\left(x^{\prime}, y\right) \in R_{+}^{p+q} \mid x^{\prime} \leq x, y \leq Y_{i}, i=1, \ldots, m\right\}$. Furthermore, the maximal output expansion can be characterised as:

$\tilde{\lambda}_{m}(x, y)=\sup \left\{\lambda>0 \mid(x, \lambda y) \in \Psi_{m}(x)\right\}$,

and the Order- $m$ output efficiency measure efficiency score is given from:

$$
\lambda_{m}(x, y)=\mathrm{E}\left(\tilde{\lambda}_{m}(x, y) \mid X \leq x\right) .
$$

Then, the Order- $m$ efficiency score can be computed as:

$$
\lambda_{m}(x, y)=\int_{0}^{\infty}\left[1-\left(1-S_{Y \mid X}(u y \mid X \leq x)\right)^{m}\right] d u .
$$

An Order-m efficiency score of less than one indicates a super-efficient level, whereas, efficiency scores equal to one suggest that the company lies on the frontier being efficient. Values greater than one indicate inefficiency (Cazals et al. 2002). If a company has a better performance compared to the $m$ randomly drawn companies with $X \leq x$ (in our case $m$ is set to 20 companies) ${ }^{5}$, then it is said to be a superefficient company. In such circumstances companies' Order- $m$ levels are below unity.

${ }^{5} \mathrm{We}$ follow Daraio and Simar (2005) and we chose a value of $m$ companies (i.e. 20) under which the number of super-efficient companies stabilizes. For higher $m$ values, the efficiency estimates converge 
For instance and in the framework of our analysis, let us consider the case where a company is estimated of an Order-m output efficiency score equal to 1.6. Then we can say that this company would perform as efficient as the $m=20$ best benchmark companies with $X \leq x$ if its value added levels could increase by $60 \%$.

By following Mastromarco and Simar's (2015) approach, the time-dependent conditional output-oriented Order- $m$ efficiency scores can be computed as ${ }^{6}$ :

$\lambda_{m, t}(x, y \mid z)=\int_{0}^{\infty}\left[1-\left(1-S_{Y \mid X, Z}^{t}(u y \mid X \leq x, Z=z, T=t)\right)^{m}\right] d u$.

As indicated by Bădin et al. (2012, 2014), we can disentangle the effects of 'R\&D expenditure' and 'time' from the efficiency levels of companies by considering the ratios of conditional to unconditional Order-m efficiency measures, which are the measures relative to the partial frontier of the conditional to the unconditional attainable sets:

$R_{m}(x, y \mid z, t)=\frac{\lambda_{m, t}(x, y \mid z)}{\lambda_{m}(x, y)}$.

We can investigate the 'R\&D expenditure' and 'time' values that are associated with the companies by looking at the behaviours of the above ratios as a function of ' $R \& D$ expenditure' and 'time'. For this purpose, we proceed by estimating the following nonparametric regression function:

$R_{m_{i, t}}=g\left(\mathrm{R} \& \mathrm{D}\right.$ expenditure ${ }_{i}$, Time $\left._{t}\right)+u_{i t}$,

where $u_{i t}$ indicates the usual error term. As suggested by Jeong et al. (2010), we apply a local linear estimator of the regression function that is less sensitive to the

quickly to the full frontiers estimates. According to Cazals et al. (2002), when $m \rightarrow \infty$ then the Order$m$ efficiency scores converge to those derived from the Free Disposal Hull-FDH (Deprins et al., 1984) estimates. Finally, Bădin et al. (2012) suggest that when $m=1$ then the Order- $m$ frontier measures a companies 'average behaviour in terms of their technical efficiency levels.

${ }^{6}$ For computational issues and programming codes, see the works of Daraio and Simar $(2005,2006$, 2007a, 2007b) and Bădin et al. (2010, 2012, 2014). 
edge effects. ${ }^{7}$ Then, for given input values, an increasing shape of $R_{m}$ as a function of 'R\&D expenditure' and 'time' would correspond to the favourable effect of R\&D and time on the efficiency levels of the companies. Meanwhile, a decreasing shape of $\mathrm{R} \& \mathrm{D}$ expenditure and time acting as undesirable outputs would signify a negative effect.

\section{Empirical Results}

Output-oriented partial frontier measures of Order- $m$ to measure the technical efficiency levels of B\&P companies were applied. Figure 2 presents the mean Order$m$ technical efficiency levels of the companies. Given the fact that efficiency scores above unity indicate higher inefficiency levels, the results suggest that firms operating in the biotechnology sector perform better (i.e. efficiency scores $<1$ ) compared to those operating in the pharmaceutical sector (i.e. efficiency scores $>1$ ). Clearly all firms performed better during the initial years of our analysis. It is of note, higher fluctuations in their estimated efficiency levels occurred, especially after the initiation of GFC. Therefore, the exposure of these companies to the GFC is also reflected on the estimated technical efficiency levels.

\section{Figure 2 about here}

Figure 3 presents the density plots of the mean efficiency estimates for the companies over the examined period. The results are presented in overlapping three-year widow basis enable to assess companies' performance before during and after the GFC period. In Figure 3 the vertical solid line indicates unity, whereas, the vertical dotted lines indicate the mean values. The density plots are presented in a three year basis (i.e. 2000-2002, 2002-2004, 2004-2006,..., 2014-2016 and 2016-2017) in order to evaluate diachronically companies' distribution of their estimated Order- $m$ efficiency measures. The results signify that companies operating in the two evaluated sectors were having increased technical efficiency levels up to the initiation of GFC period (i.e. year 2007). This is evident on the subfigures 3a to 3d signified with the mass of

\footnotetext{
${ }^{7}$ For the smoothing parameter (also called bandwidth) of the local linear estimation we have applied the Least Squares Cross-Validation-LSCV criterion (Hall et al., 2004; Li and Racine, 2007).
} 
the distribution located to the left of the blue solid line (i.e. unity). However, during and after the period of GFC (i.e. subfigures $3 e$ to $3 i$ ) companies are reported to have higher inefficiency levels indicated with the mass of their efficiency densities to be located to the right of the unity. As a result it is suggested that GFC had a negative impact on their estimated efficiency levels suggesting that companies were not able to fully recover and obtain similar technical efficiency levels as those obtained during the pre-crisis period (i.e., 2000-2007).

Figure 3 about here

Previously defined ratios from the unconditional and conditional Order- $m$ estimates were used to examine the effects of $R \& D$ expenditures on the production processes of companies. As Daraio and Simar (2007a) suggest, partial frontiers produce robust estimators to deal with issues related to outliers and extreme values, which can mask the effect of the examined factors on the estimated production process.

In our case, $R_{m}(x, y \mid z, t)$ as a function of $\mathrm{R} \& \mathrm{D}$ expenditure and time, provides information about the potential effects on companies' estimated efficiency distributions.

Figure 4 present's three-dimensional illustrations of the examined effects for the sample (Figure 4a), the subsample of the firms that operate in biotechnology sector (Figure $4 \mathrm{~b}$ ) and for the subsample of firms that operate in pharmaceutical sector (Figure 4c). When examining the three-dimensional picture for the sample, it is of noteworthy interest to see that the relationships between time, $R \& D$ expenditures and technical efficiency is nonlinear.

This nonlinear finding suggests the presence of increasing and decreasing returns, as indicated by the reported threshold value. On further examination the effects of R\&D expenditures on the efficiency levels of companies signifying a clear ' $U$ '-shaped relationship between the $R \& D$ expenditures of the companies and their technical efficiency levels can be seen. This indicates that when firms increase their R\&D expenditure levels, this does not have a positive effect on their technical efficiency 
levels. However, after a threshold value the effect becomes positive suggesting that increased R\&D expenditures will result in an increase technical efficiency of companies.

Figure $4 b$ indicates the effect of time and $R \& D$ expenditures on the technical efficiency levels of firms operating in biotechnology sector. The three-dimensional picture presents again a ' $U$ '-shaped relationship between the $R \& D$ expenditures and technical efficiency of the companies. As previously this suggests a clear positive effect on efficiency levels for higher R\&D expenditure, as signified by the increasing nonparametric regression line (after a threshold value). However, this effect becomes negative for lower $R \& D$ expenditures, thus suggesting the presence of diminishing returns. When examining the effect of time, the evidence suggests that there is a positive effect until the GFC began. However, the effect of time on the efficiency levels of the companies is negative after this point, which is indicated by a decreasing line. This finding supports the views of Lee et al. (2015) who suggest that the financial crisis had a negative effect on innovation-based firms.

Figure $4 c$ presents the effects of $R \& D$ expenditures and time on the technical efficiency levels of firms that operate only in pharmaceutical sector. The results indicate again a ' $U$ '-shaped relationship between $R \& D$ expenditures and the efficiency levels of the companies. The three-dimensional picture reveals that the effect is negative for lower $R \& D$ expenditures. Then after a certain threshold point the effect becomes positive for higher R\&D expenditures levels. As for the time effect, it is evident that there is a nonlinear positive effect on firms' estimated technical efficiency levels.

The overall results signify an overall nonlinear relationship between time, R\&D expenditures and the technical efficiency. It is evident that there is a "U"-shape relationship among firms' technical efficiency levels and their R\&D expenditures. 


\section{Conclusions and Implications}

The applied methodological framework adopted allowed the exploration of a link between R\&D expenditures and the efficiency of companies. This research has demonstrated that a company efficiency is an important contributor to current $R \& D$ activity and that upstream spill overs on productivity and efficiency exist. The use of a balanced data set provides a better understanding of how biotechnology \& pharmaceutical firms operate. In addition, current research on this sector has failed to analyse the behaviours of businesses during the GFC.

The main results are as follows: pharmaceutical firms exhibit lower performance levels compared to the companies operating on the biotechnology sector.

The data suggests that the GFC negatively affected the performance of companies that operate in the U.S. biotechnology and pharmaceutical sectors from 2008-2017. Thus, this research provides an important contribution by revealing how the volume of R\&D expenditures affected the performance of companies during this period.

It is also suggested that $R \& D$ expenditures have a ' $U$ '-shaped relationship with company performance. This result is confirmed for both types of firms (i.e., those that operate in biotechnology and pharmaceutical sectors). This is an important finding since it indicates that an optimal level of $R \& D$ exists. This can also be seen when time is considered, as a ' $U$ '-shaped relationship is present.

This study also provides some important policy recommendations for managers. It is proposed that $R \& D$ expenditures are essential for the efficiency of all $B \& P$ firms. However, a threshold for achieving optimal efficiency levels exist and managers need to be mindful to balance investment with return on investment or innovation. Firms must review their allocation of $R \& D$ expenditures in their production processes carefully.

The results also propose that recent cuts in the numbers of employees have positively affected the efficiency of the companies examined in this research. However, these changes will only improve the fortunes of shareholders in the short term. Further 
investigation is required to explore how these corporate changes will affect the development of new drugs and products as part of the innovation pipeline. This is because a high rate of return on $R \& D$ expenditure, as a proxy measure for innovation, no longer guarantees high yields. Thus, optimal R\&D investment can yield a positive return, while the over-adoption of innovation can harm the efficiency of a firm.

$\mathrm{B} \& \mathrm{P}$ companies will continue to compete vigorously, embrace new forms of innovation and introduce additional processes and financial innovations. They will also engage in patent disputes with generic brands, manage drug pipelines and leverage existing and new patents more effectively, while developing strategic alliances.

This suggests that there may be room for further consolidation and international expansion through M\&As for exploring new product innovations for diseases that are not yet on the radar to maximise revenue streams. M\&As can improve two important aspects related to company efficiency: namely $R \& D$ expenditure and technical efficiency until the company 'hits' the threshold limit.

$\mathrm{B} \& \mathrm{P}$ firms are likely to continue to engage in $\mathrm{R} \& \mathrm{D}$, from chemical-based small molecules research to biology-based large molecules, such as antibodies and proteinbased innovations, as they are likely to always be undertaking $R \& D$, but perhaps now they will focus on finding the optimal balance between $R \& D$ expenditure and technical efficiency. 
Appendix 1: Names of the pharmaceutical companies examined in this study

Biotechnological firms (97):

ABEONA THERAPEUTICS INC, AGENUS INC, ALEXION

PHARMACEUTICALS INC, ALKERMES PLC, AMAG PHARMACEUTICALS

INC, AMARILLO BIOSCIENCES INC, AMARIN CORP, AMGEN INC, AMPLIPHI BIOSCIENCES CORP, ARENA PHARMACEUTICALS INC, ARQULE INC, ARROWHEAD PHARMACEUTICALS, AVID BIOSERVICES INC, BIOCRYST PHARMACEUTICALS INC, BIOGEN INC, BIOMARIN PHARMACEUTICAL INC, BIOSPECIFICS TECHNOLOGIES CP, BIOTIME INC, CALADRIUS BIOSCIENCES INC, CAPSTONE THERAPEUTICS CORP, CASI PHARMACEUTICALS INC, CELGENE CORP, CEL-SCI CORP, CELSION CORP, CTD HOLDINGS INC, CTI BIOPHARMA CORP, CURIS INC, CYTRX CORP, DIADEXUS INC, ENZON PHARMACEUTICALS INC , EXACT SCIENCES CORP, EXELIXIS INC, EXPEDEON AG, FIBROCELL SCIENCE INC, GENEREX BIOTECHNOLOGY CORP, GEOVAX LABS INC, GERON CORP, GILEAD SCIENCES INC, GT BIOPHARMA INC, HEMISPHERX BIOPHARMA INC, HERON THERAPEUTICS INC, IDERA PHARMACEUTICALS INC, IMMUCELL CORP, IMMUNOGEN INC, IMMUNOMEDICS INC, INCYTE CORP, INOVIO PHARMACEUTICALS INC, INSMED INC, IONIS PHARMACEUTICALS INC, ISORAY INC, ITUS CORP, KAZIA THERAPEUTICS LTD, KERYX BIOPHARMACEUTICALS INC, LA JOLLA PHARMACEUTICAL CO, LEXICON PHARMACEUTICALS INC, LIGAND PHARMACEUTICAL INC, MANHATTAN SCIENTIFICS INC, MATEON THERAPEUTICS INC, MYMETICS CORP, MYRIAD GENETICS INC, NAVIDEA BIOPHARMACEUTICALS, NEUROCRINE BIOSCIENCES INC, NORTHWEST BIOTHERAPEUTICS, NOVAVAX INC, NYMOX PHARMACEUTICAL CORP, ONCOVISTA INNOVATIVE THERAP, OPKO HEALTH INC, PALATIN TECHNOLOGIES INC, PDL BIOPHARMA INC, POLARITYTE INC, PRANA BIOTECHNOLOGY LTD, PROGENICS PHARMACEUTICAL INC, PROTALEX INC, PROTALIX BIOTHERAPEUTICS INC, REGENERON PHARMACEUTICALS, REGENERX BIOPHARMACEUTICALS, REPLIGEN CORP, RIGEL PHARMACEUTICALS INC, SANGAMO THERAPEUTICS INC, SAREPTA THERAPEUTICS INC, SEATTLE GENETICS INC, SHIRE PLC, SINOVAC BIOTECH LTD, SOLIGENIX INC, SPECTRUM PHARMACEUTICALS INC, STEMCELLS INC, TG THERAPEUTICS INC, TIKCRO TECHNOLOGIES LTD, UNITED THERAPEUTICS CORP, VERICEL CORP, VERNALIS PLC, VERTEX PHARMACEUTICALS INC, VG LIFE SCIENCES INC, VICAL INC, VITRO DIAGNOSTICS INC, WINDTREE THERAPEUTICS INC, XOMA CORP.

Pharmaceutical firms (52):

ACURA PHARMACEUTICALS INC, AEOLUS PHARMACEUTICALS INC, AKORN INC, ALLERGAN PLC, AOXING PHARMACEUTICAL CO INC, APRICUS BIOSCIENCES INC, ARADIGM CORP, ARALEZ PHARMACEUTICALS INC, ASSERTIO THERAPEUTICS INC, ASTRAZENECA PLC, AVADEL PHARMACEUTICALS -ADR, BAUSCH HEALTH COMPANIES INC, BAYER AG, BIODELIVERY SCIENCES INTL, BRISTOL-MYERS SQUIBB CO, CORCEPT THERAPEUTICS INC, DR REDDY'S LABORATORIES LTD, DURECT CORP, EISAI CO LTD, ELITE PHARMACEUTICALS INC , MISPHERE TECHNOLOGIES INC, ENDO INTERNATIONAL PLC, 
GLAXOSMITHKLINE PLC, HEDGEPATH PHARMACEUTICALS, JOHNSON \& JOHNSON, JUNIPER PHARMACEUTICALS INC, LANNETT CO INC,

LESCARDEN INC, LILLY (ELI) \& CO, MEDICINES CO, MERCK \& CO,

MYLAN NV, NEKTAR THERAPEUTICS, NOVARTIS AG, NOVO NORDISK

A/S, PAIN THERAPEUTICS INC, PERRIGO CO PLC, PFIZER INC, PHIBRO

ANIMAL HEALTH CORP, POLYDEX PHARMACEUTICALS LTD, PROPHASE LABS INC, PROVECTUS BIOPHARMACEUTICALS, RESPIRERX

PHARMACEUTICALS, ROCHE HOLDING AG, ROCK CREEK

PHARMACEUTICALS, SANOFI, SIGA TECHNOLOGIES INC, TARO

PHARMACEUTICL INDS LTD, TELIGENT INC, TEVA PHARMACEUTICALS, TITAN PHARMACEUTICALS INC, VIVUS INC. 


\section{References}

Bădin, L., Daraio, C., Simar, L. (2010). Optimal bandwidth selection for conditional efficiency measures: a data-driven approach. European Journal of Operational Research, 201(2), 633-640.

Bădin, L., Daraio, C., Simar, L. (2012). How to measure the impact of environmental factors in a nonparametric production model. European Journal of Operational Research, 223, 818-833.

Bădin, L., Daraio, C., Simar, L. (2014). Explaining inefficiency in nonparametric production models: the state of the art. Annals of Operations Research, 214, 5-30.

Booz \& Company (2009). Transforming the Value Proposition in Pharmaceutical Marketing, http://www.strategyand.pwc.com/media/file/Transforming the Value_Proposition_in _Pharmaceutical_Marketing.pdf, [Accessed on 7 September (2015)].

Brautzsch, H.-U., Gunther, J., Loose, B., Ludwig, U., Nulsch, N., (2015). Can R\&D subsidies counteract the economic crisis? Macroeconomic effects in Germany. Research Policy 44, 623-633.

Brem, A., Nylund, P.A., and Schuster, G., (2016). Innovation and de facto standardization: The influence of dominant design on innovative performance, radical innovation, and process innovation, Technovation, 50-51.

Campello, M., Gambon, E., Graham, JR., Harvey, CR. (2011). Liquidity Management and Corporate Investment During a Financial Crisis, Review of Financial Studies 24, 1944-1979.

Castellani, D., Pieri, F. (2013). R\&D offshoring and the productivity growth of European regions', Research Policy 42, 1581-1594.

Cazals, C., Florens, J. P., Simar, L. (2002). Nonparametric frontier estimation: a robust approach. Journal of Econometrics, 106, 1-25. 
Chang, S. Y., \& Chen, T. H. (2008). Performance ranking of Asian lead frame firms: a slack-based method in data envelopment analysis. International Journal of Production Research, 46(14), 3875-3885.

Co, H. C., \& Chew, K. S. (1997). Performance and R\&D expenditures in American and Japanese manufacturing firms. International Journal of Production Research, 35(12), 3333-3348.

Cohen, WM., Levinthal, DA. (1989). Innovation and learning: The two faces of R\&D., Economic Journal 99, 569-596.

Daraio, C., Simar, L. (2005). Introducing environmental variables in nonparametric frontier models: a probabilistic approach. Journal of Productivity Analysis, 24, 93-121.

Daraio, C., Simar, L. (2006). A robust nonparametric approach to evaluate and explain the performance of mutual funds. European Journal of Operational Research, 175(1), $516-542$.

Daraio, C., Simar, L. (2007a). Advanced robust and nonparametric methods in efficiency analysis. Methodology and applications. New York: Springer.

Daraio, C., Simar, L. (2007b). Conditional nonparametric frontier models for convex and non-convex technologies: a unifying approach. Journal of Productivity Analysis, 28, $13-32$.

Daraio, C., Simar, L., \& Wilson, P. W. (2018). Central limit theorems for conditional efficiency measures and tests of the 'separability' condition in non-parametric, twostage models of production. Econometrics Journal, 21, 170-191.

Debreu, G. (1951). The coefficient of resource utilization. Econometrica, 19(3), 273-292.

Deprins D, Simar L, Tulkens H (1984). Measuring labor inefficiency in post offices. In: Marchand M, Pestieau P, Tulkens H (eds) The performance of public enterprises: concepts and measurements. Amsterdam, North-Holland, 243-267.

Farrell, M. J. (1957). The measurement of the productive efficiency. Journal of the Royal Statistical Society Series A, CXX(3), 253-290. 
González, E., Gascón, F., (2004). Sources of Productivity Growth in the Spanish Pharmaceutical Industry (1994-2000). Research Policy 33, 735-745

Griffith, R., Redding, S., Van Reenen, J., (2004). Mapping the Two Faces of R\&D: Productivity Growth in a Panel of OECD Industries, Review of Economics and Statistics 86, 883-895.

Griliches, Z., Lichtenberg, F. (1984). Interindustry Technology Flows and Productivity Growth: A Re-examination, The Review of Economics and Statistics 66, 324-329.

Groot, T., García-Valderrama, T. (2006). Research quality and efficiency: An analysis of assessments and management issues in Dutch economics and business research programs. Research Policy, 35, 1362-1376.

Grossman, GM., Helpman, E. (1991). Trade, knowledge spillovers, and growth, European Economic Review 35, 517-526.

Hall, B. H., Mairesse, J., (1995). Exploring the Relationship Between R\&D and Productivity in French Manufacturing Firms, Journal of Econometrics 65, 263-293.

Hall, P., Racine, J.S., Li, Q., (2004). Cross-validation and the estimation of conditional probability densities. Journal of the American Statistical Association 99, 1015-1026.

Hossein Safizadeh, M., \& Murphy, D. C. (1992). Effect of R\&D product and process expenditures on new product introductions. The International Journal Of Production Research, 30(12), 2921-2939.

Jeong, S.O., Park, B.U., Simar, L., (2010). Nonparametric conditional efficiency measures: asymptotic properties. Annals of Operations Research 173, 105-122.

Kessel, M. (2011). The problems with today's pharmaceutical business-An outsider's view, Nature Biotechnology 29, 27 - 33.

Lee, N., Sameen, H., Cowling, M., (2015). Access to finance for innovative SMEs since the financial crisis. Research Policy 44, 370-380. 
Li, Q., Racine, J.S., (2007). Nonparametric Econometrics: Theory and Practice, Princeton University Press.

Lowman, M., Trott, P., Hoecht, A., and Sellam, Z., (2012). Innovation risks of outsourcing in pharmaceutical new product development, Technovation, 32, 2, 99-109.

Mazzucato, M. and Parris, S. (2014) "High growth firms in competitive environments: the US pharmaceutical industry (1963 to 2002)" Small Business Economics Journal, 43(1).

Mairesse, J., Sassenou, M., (1991). R\&D and Productivity: A Survey of Econometric Studies at the Firm Level. Science-Technology-Industry Review 8, 317-348.

Mastromarco, C., Simar, L. (2015). Effect of FDI and time on catching up: New insights from a conditional nonparametric frontier analysis. Journal of Applied Econometrics, $30,826-847$.

McKinsey \& Company Pharmaceuticals \& Medical Products(2017) Rethinking pharma productivity by Gayane Gyurjyan, Shail Thaker, Kirsten Westhues, and Carla Zwaanstra .https://www.mckinsey.com/industries/pharmaceuticals-and-medicalproducts/our-insights/rethinking-pharma-productivity

Delgado-Verde, M., Martín-de Castro, G., Amores-Salvadó, J., (2016) Intellectual capital and radical innovation: Exploring the quadratic effects in technology-based manufacturing firms, Technovation, 54, 35-47.

O'Mahony, M., Vecchi, M., (2009). R\&D, knowledge spillovers and company productivity performance‘, Research Policy 38, 35-44.

Pammolli, F., Riccaboni, M., Magazzini, L. (2011). The productivity crisis in pharmaceutical R\&D, Nature Reviews Drug Discovery 10, 428-438.

Scannell, JW, Blanckley A, Boldon H, Warrington, B. (2012). Diagnosing the decline in pharmaceutical R\&D efficiency. Nature Reviews Drug Discovery 11, 191-200.

Simar, L., Wilson, P.W., (2011). Two-stage DEA: Caveat Emptor. Journal of Productivity Analysis 36, 205-218. 
Tsaur, R. C., Chen, I. F., \& Chan, Y. S. (2017). TFT-LCD industry performance analysis and evaluation using GRA and DEA models. International Journal of Production Research, 55(15), 4378-4391.

Venturini, F., (2015). The modern drivers of productivity, Research Policy 44, 357-369.

Wang, K., (2014). Mizuho Industry Focus Restructuring the Pharmaceutical Industry Vol. 155.

Wang, E.C., Huang, W. (2007). Relative efficiency of R\&D activities: A cross-country study accounting for environmental factors in the DEA approach. Research Policy, 36, $260-273$.

Wang, R. T., Ho, C. T. B., \& Oh, K. (2010). Measuring production and marketing efficiency using grey relation analysis and data envelopment analysis. International Journal of Production Research, 48(1), 183-199.

Wang, W. K., Chan, Y. C., Lu, W. M., \& Chang, H. (2015). The impacts of asset impairments on performance in the Taiwan listed electronics industry. International Journal of Production Research, 53(8), 2410-2426.

Zanders, ED., (2011) The Science and Business of Drug Discovery, Commercial Aspects of Drug Development pp 305-328| 
Table 1: Descriptive statistics of the variables

\begin{tabular}{|c|c|c|c|c|c|}
\hline & & Property, Plant and Equipment & Employees & Value added & Research and Development Expenditure \\
\hline \multirow[t]{2}{*}{2000} & Mean & 2310.208 & 5.693 & 3129.577 & 228.544 \\
\hline & Std & 7905.388 & 20.048 & 11311.287 & 726.271 \\
\hline \multirow[t]{2}{*}{2001} & Mean & 2574.367 & 5.847 & 3332.884 & 256.329 \\
\hline & Std & 8735.214 & 20.435 & 12221.859 & 844.161 \\
\hline \multirow[t]{2}{*}{2002} & Mean & 2978.619 & 6.123 & 3737.836 & 290.163 \\
\hline & Std & 9864.382 & 21.302 & 13581.434 & 914.772 \\
\hline \multirow[t]{2}{*}{2003} & Mean & 3733.153 & 6.245 & 3921.525 & 368.702 \\
\hline & Std & 13550.284 & 21.662 & 13716.805 & 1335.326 \\
\hline \multirow[t]{2}{*}{2004} & Mean & 4649.106 & 6.689 & 4443.344 & 431.046 \\
\hline & Std & 16630.107 & 22.440 & 15194.270 & 1446.351 \\
\hline \multirow[t]{2}{*}{2005} & Mean & 4662.218 & 6.677 & 4626.441 & 408.757 \\
\hline & Std & 16413.541 & 22.028 & 15467.716 & 1308.770 \\
\hline \multirow[t]{2}{*}{2006} & Mean & 5233.533 & 7.070 & 5140.204 & 503.806 \\
\hline & Std & 17774.340 & 22.966 & 16839.482 & 1499.914 \\
\hline \multirow[t]{2}{*}{2007} & Mean & 5840.323 & 7.054 & 5688.741 & 565.848 \\
\hline & Std & 19095.256 & 22.624 & 18512.966 & 1651.542 \\
\hline \multirow[t]{2}{*}{2008} & Mean & 5900.110 & 7.027 & 5778.426 & 591.596 \\
\hline & Std & 18988.941 & 22.373 & 18413.830 & 1743.657 \\
\hline \multirow[t]{2}{*}{2009} & Mean & 7543.673 & 7.586 & 6128.878 & 556.114 \\
\hline & Std & 26522.827 & 24.284 & 19296.649 & 1685.112 \\
\hline \multirow[t]{2}{*}{2010} & Mean & 7733.551 & 7.652 & 6833.036 & 634.610 \\
\hline & Std & 26175.661 & 24.341 & 21530.030 & 1979.026 \\
\hline \multirow[t]{2}{*}{2011} & Mean & 8066.947 & 7.847 & 7115.086 & 621.680 \\
\hline & Std & 26576.221 & 24.630 & 22086.838 & 1865.955 \\
\hline \multirow[t]{2}{*}{2012} & Mean & 8457.296 & 7.935 & 7193.504 & 646.668 \\
\hline & Std & 27206.962 & 24.660 & 21980.821 & 1909.470 \\
\hline \multirow[t]{2}{*}{2013} & Mean & 8817.582 & 8.023 & 7386.796 & 660.933 \\
\hline & Std & 27298.997 & 24.676 & 22209.733 & 1895.441 \\
\hline \multirow[t]{2}{*}{2014} & Mean & 9228.462 & 8.188 & 7310.369 & 682.475 \\
\hline & Std & 27084.319 & 24.815 & 21142.961 & 1873.023 \\
\hline \multirow[t]{2}{*}{2015} & Mean & 10589.943 & 8.524 & 7396.565 & 723.216 \\
\hline & Std & 29430.312 & 24.930 & 20638.986 & 1893.273 \\
\hline \multirow[t]{2}{*}{2016} & Mean & 11333.438 & 8.596 & 7625.388 & 783.074 \\
\hline & Std & 30537.949 & 24.699 & 20811.788 & 2057.719 \\
\hline \multirow[t]{2}{*}{2017} & Mean & 11503.735 & 8.494 & 8013.522 & 857.062 \\
\hline & Std & 30950.820 & 24.429 & 21783.262 & 2211.754 \\
\hline
\end{tabular}


Figure 1: Diachronic representation of firms' $R \& D$ expenditure and $R \& D$ intensity levels

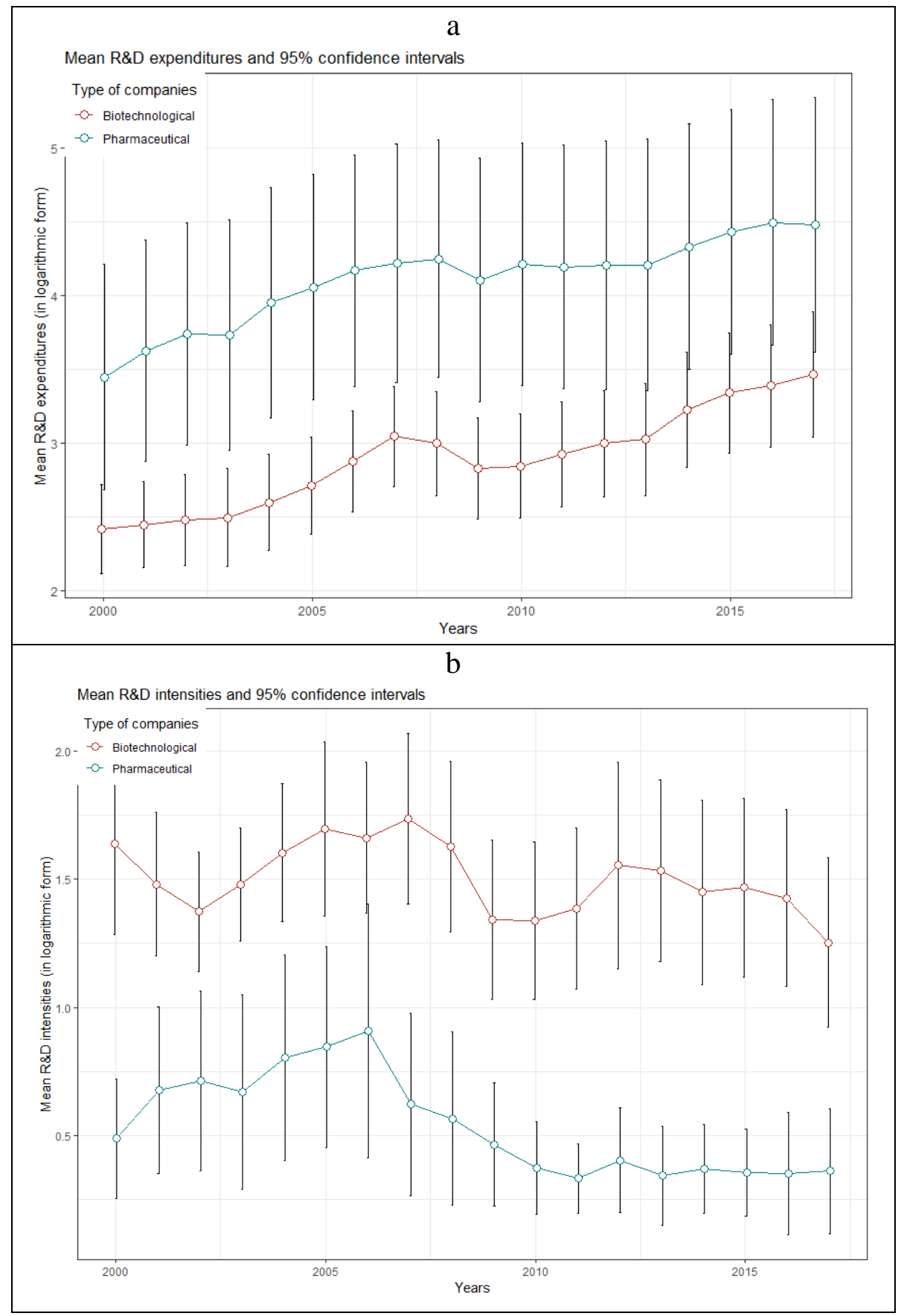


Figure 2: Diachronic representation of firms' mean Order- $m$ efficiency levels

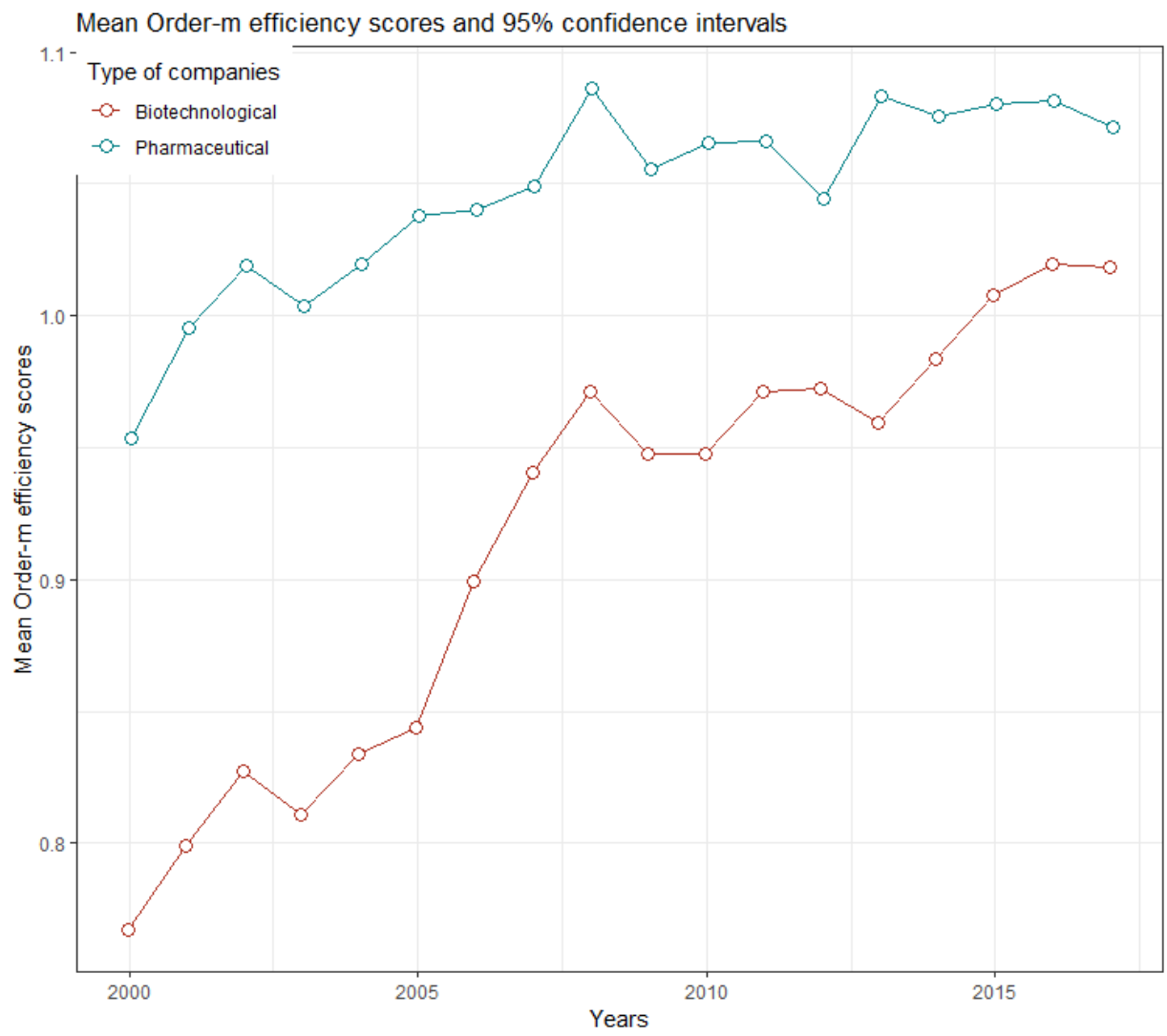


Figure 3: Estimated density plots of companies Order- $m$ efficiency scores based on three-year overlapping widows.

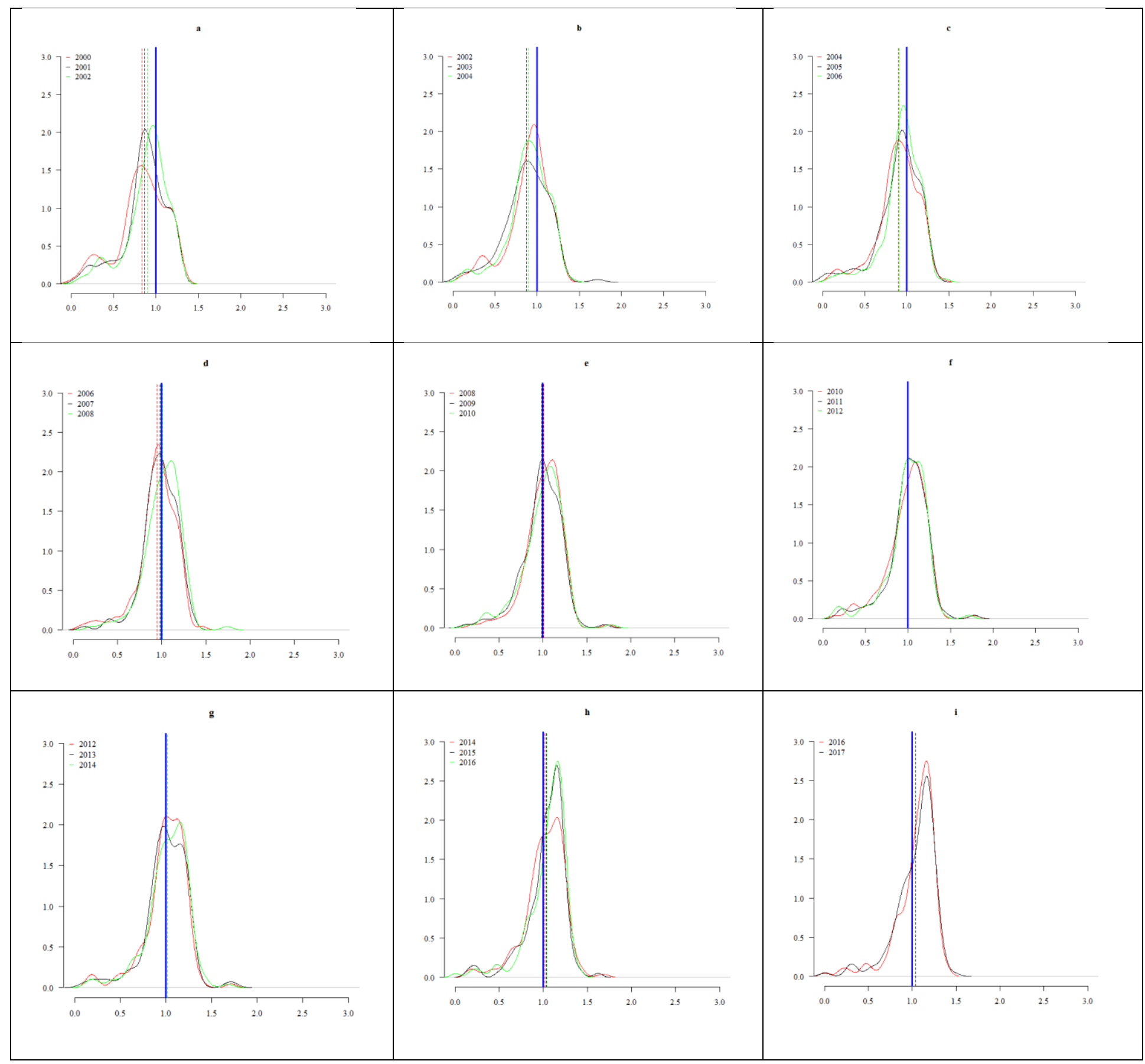


Figure 4: The effect of time and $R \& D$ expenditure on companies' performance

The effect of 'Time' and 'R\&D spending'-Entire sample

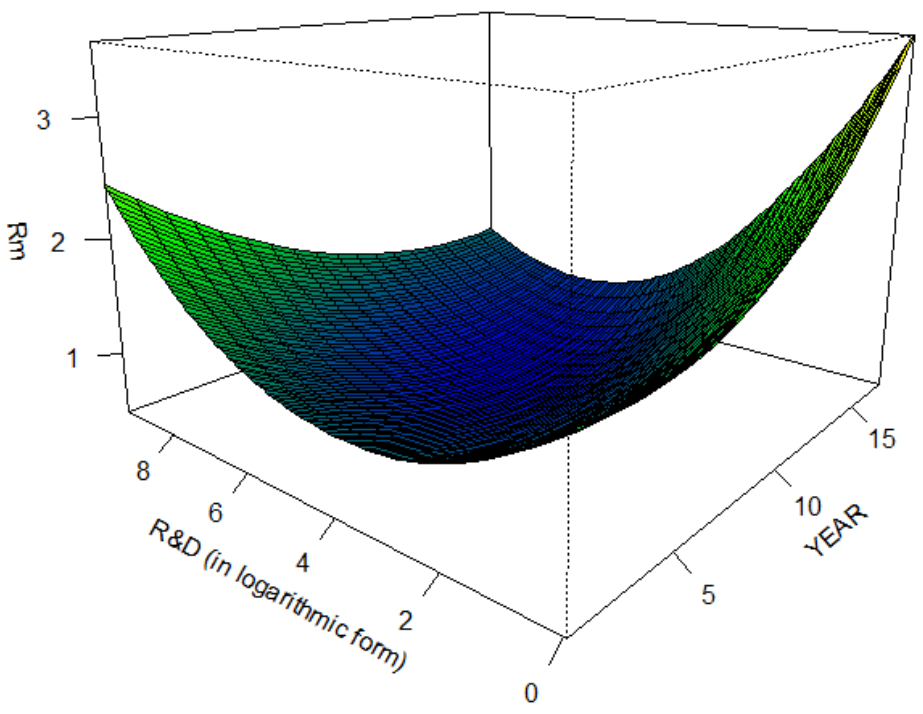

b

The effect of 'Time' and 'R\&D spending'-Biotechnological firms

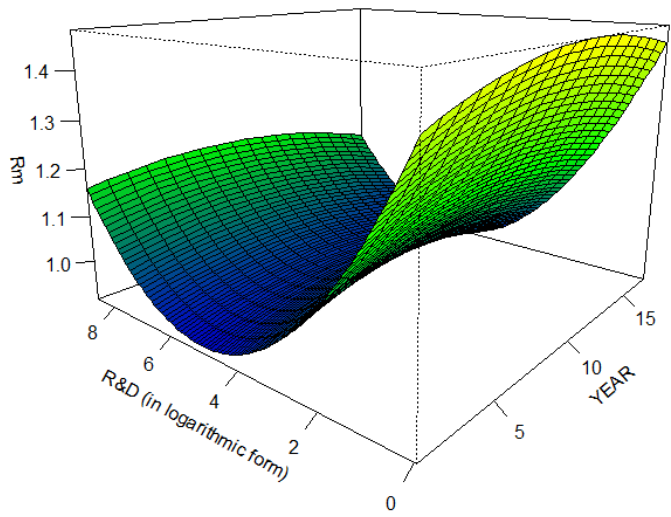

$\mathrm{c}$

The effect of 'Time' and 'R\&D spending'-Pharmaceutical firms

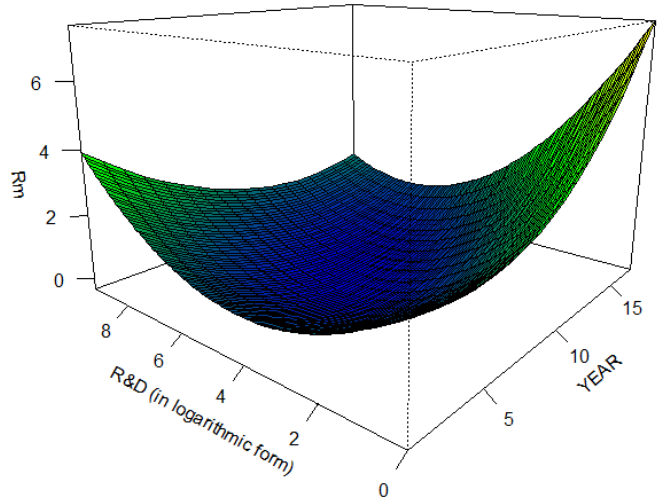


